\title{
MARIA LÚCIA FATTORELLI - AUDITORIA CIDADÃ DA DÍVIDA DOS ESTADOS
}

\author{
Pollyanna Araújo Carvalho ${ }^{1}$
}

Referência da obra resenhada:

Fattorelli, Maria Lúcia. Auditoria Cidadã da Dívida dos Estados. Brasília: Editora Inove, 2013.

É emblemático que a autora comece seus estudos nesse livro a partir da epígrafe de um discurso de Henry Ford ainda em 1922, para quem "é bom que o povo não entenda nosso sistema bancário e monetário, porque se entendesse, acho que haveria uma revolução antes de amanhã". Isso marca um ponto importante sobre as novas exigências quanto à transparência, a crítica e à reflexão concernentes aos estudos e ao funcionamento social da Dívida Pública.

Ler e falar da Dívida Brasileira é imergir na própria história, na própria cultura de constituição de endividamento, fato que motivou estudiosos a se envolverem nas leituras, nos debates, estreitando assim as suas relações com a temática sob a perspectiva da disseminação do conhecimento. No livro Auditoria Cidadã da Dívida dos Estados, a contabilista e administradora Maria Lúcia Fattorelli Carneiro, Coordenadora Nacional da Auditoria Cidadã da Dívida desde a fundação do movimento no ano 2001, elabora um panorama por meio do trabalho de mais de 10 anos de pesquisas cujo interesse é dos mais relevantes para a compreensão da democratização do conhecimento a respeito do endividamento público no Brasil.

O presente livro, em edição esgotada, aponta de forma didática e acessível os fatos que aguçam a discussão, embora ainda tímida e velada no meio acadêmico e muito menos ainda na esfera popular, disso que pudemos chamar de assombrosa dívida pública brasileira.

Nos primórdios do movimento da Auditoria Cidadã da Dívida em 2001, Fattorelli iniciara a crítica sistemática da distribuição de renda desigual, bem como do desenvolvimento humano ínfimo - se relacionados com a riqueza nacional - sobreposto ao seguinte paradoxo: a interpretação

\footnotetext{
${ }_{1}$ Mestranda em Crítica Cultural na Universidade do Estado da Bahia (UNEB). Endereço eletrônico: pollyannacarvalho1@hotmail.com.
}

Pontos de Interrogaçầo, v. 7, n. 2, jul.-dez., p. 149-154, 2017. 
mercadológica privilegia os mais ricos e penalizam os trabalhadores, os quais geram e movem a economia do país.

Tal exegese explicita o fator histórico da tradição da sociedade brasileira de aceitar, sem contestar, as dívidas herdadas desde a compra de sua independência - e que segue rolada e atualizada de governo em governo. Essa característica abrupta da dívida é radicalmente criticada e contestada ao decorrer dos argumentos apresentados no livro, no qual a autora argumenta que foi criado um sistema da dívida absolutamente equivocado, em seu conjunto, além de não apresentar provas documentais e de servir, apenas para transferir recursos do setor público para os setores privados, nacionais e internacionais.

Avaliando os efeitos desse crime financeiro ao longo dos séculos, a partir dos argumentos apontados no texto por Fattorelli, pode-se inferir, em primeiro lugar, que o cidadão tem a todo o momento os seus direitos sociais esfacelados por esse sistema da dívida, o que categoriza sua permanência nesse processo de impossibilidade de libertação das subordinações socioeconômicas, submisso aos ditames do mercado financeiro.

À vista disso, a sistematização do mercado financeiro preconiza a cordialidade do poder estatal com arcabouço da elite, a qual se mantem à luz da Constituição Federal de 1988 e corrobora com a personalização da camada da população que se anseia beneficiar: os arquimilionários detentores/credores da dívida.

Em sentido amplo, o livro fundamentado em pesquisa empírica remonta a realidade dos estados sobre a configuração do endividamento, em que sua objeção à mera sobredeterminação superficial que permeia a sociedade, envolve as relações de poder infensas à ação institucional do Estado e mercado capitalistas, desde logo efetivos, em um processo de "europeização" e "americanização", principalmente observado na fuga dos capitais, que data da chegada da família real ao país.

Central nesse pilar hermenêutico, a estudiosa traveja com notável desenvoltura, a experiência na auditoria obtida em outros países latinos e europeus que viabiliza um olhar caleidoscópico da dívida. No Equador entre 2007 e 2008, atuou na subcomissão de dívida externa comercial, engendrando resultados e a efetivação da auditoria, que anulou cerca de $70 \%$ da dívida. Com efeito, foram direcionados investimentos para saúde, educação e 
infraestrutura, permitindo que o déficit secular tivesse uma interface na reestruturação psicossocial da população.

Considerando a carência massiva de capital social e cultural afeta diretamente grande parte da população que necessita e clama por políticas públicas, a autora defenderá o partilhamento das experiências dos países, tanto na configuração da dívida quanto em estratégias de enfrentamento: a efetivação de auditorias cidadãs que envolvam a população objetivando a transparência e justiça. Destarte, teríamos o desvelamento do sigilo que envolve a oneração do dinheiro público, podendo, de fato, ser revertido em favor dos milhões de cidadãos brasileiros que sempre pagam o erário.

Em Auditoria Cidadã da Dívida dos Estados a agenda teórica nutrese de informações defasadas, poucos dados claros e disponíveis para consulta popular, ou até mesmo para o público especializado. No entanto, com a necessidade de investigar as vicissitudes da dívida pública, e por meio da defasagem dos dados, foi criada a Comissão Parlamentar de Inquéritos. Apesar do pouco tempo da sua implantação, a averiguação das incongruências dos conteúdos em relação à sua difusão nacional acarretou a suspensão da CPI por parlamentares contrários as informações averiguadas.

O argumento de Fattorelli demonstra substâncias efetivas no debate hodierno da dívida, mesmo diante de informações em constante mutação. O esforço da descoberta da legitimidade e legalidade despertaram muitas lutas e empecilhos para os pesquisadores por não existirem, ou não serem disponibilizados, os contratos ou documentos para uma averiguação desse sistema que até então se mostra fraudulento, camuflado com aparato jurídico.

Uma das inúmeras contribuições do texto em relação ao sistema da dívida pública, em âmbito global, é a ponderação sobre a aproximação do modus operandi dos processos de endividamento nos diversos países europeus e latinos.

Sob essa exegese, o texto supracitado sintetiza um longo percurso da crise financeira mundial, com recorte na crise estadunidense de 2008 e a europeia de 2009, bem como recupera em seus diversos capítulos a ação da grande mídia neste processo de caos e proposta de salvamento financeiro: à sombra da fuga de capitais com emissão de títulos pagos com taxas acima da praticada no sistema financeiro, a saber, a taxa SELIC - Sistema Especial de Liquidação e Custódia. 
Ademais, enfatiza o impacto dos rentistas que se beneficiam com taxas elevadas de rentabilidade, diversas medidas provisórias e leis para beneficiar o sistema de pagamento do erário, isto é, processo de mitigar os riscos para a população, principalmente os funcionários públicos brasileiros que, segundo a autora, estão sendo alvo de perseguições desde $2008 \mathrm{com}$ a expropriação econômica dos trabalhadores para a elite - a exemplo da aposentadoria.

Ressalto aqui os esclarecimentos levados a cabo por a autora na última parte do livro, os quais apontam a auditoria como forma de investigar documentos e dados que podem ser oficiais, parlamentar ou cidadã, bem como as experiências da auditoria no Equador, Portugal, Irlanda, França e Grécia. A própria nomeação de Fattorelli para algumas comissões tanto no Brasil quanto fora do país, apresenta notável competência, principalmente na condução estratégica e ética, das auditorias.

Tais experiências são disseminadas cuidadosamente por Fattorelli e avançam gradualmente até os atuais conflitos salutares de abordagem metodológica tão discutida em sua pesquisa. Todo esse esforço situa Auditoria Cidadã da Dívida dos Estados na linha de continuidade da discussão a respeito do endividamento, é posto o argumento de que o antídoto para o sistema da dívida é uma auditoria cidadã.

Estudos no cerne das ciências econômicas e sociais, muitas vezes, contrafazem o Brasil ao longo de sua história, impossibilitando uma crítica reflexiva na análise dos dados. Longe disso, Auditoria cidadã busca estabelecer travas reflexivas às ideologias hegemônicas e relações de poder que circunscrevem e utilizam dos discursos, assim como arcabouço legal para galgar uma legitimidade do endividamento. Deste modo, o livro é radical no enfrentamento isento de complacência com o que desbanca os bordões de legalidade e da falsa neutralidade institucional do governo frente ao mercado.

Os argumentos contidos enfatizam incansavelmente a falta de transparência e documentos que provem as inúmeras contradições até então encontradas no pequeno e restrito acesso aos dados de interesse nacional, os quais desvelam a desigualdade social latente que condena o Brasil ao futuro medíocre antevisto a cada dia - se continuarmos neste cenário inerte de velamento.

Dito isso, a pesquisa oferece ao leitor informações no âmago da dívida pública, de seu sistema, do mercado e da auditoria cidadã, sendo que 
esta última deve ser entendida como uma espécie de soro para desembaraçar e desvelar os engodos que confundem pagamento legítimo e legal. Ademais, evidencia, por meio da análise dos dados e documentos pela população, os privilégios legados do mercado que reproduz a lucratividade capitalista dos rentistas através do recebimento de juros sobre juros, o que penaliza e furta de forma naturalizada as classes populares.

Tais contribuições aproximam para um entendimento acessível, com o intuito de difundir, a partir dos núcleos da auditoria cidadã, a vasta produção de conhecimento que não se restringe as ciências exatas, pelo contrário, ela se submete ao extenso campo das ciências humanas, embebidas na realidade social, na vida cotidiana de todos os brasileiros. Desse modo, teriam informações e dados capazes de revolucionar e contestar o sistema imposto.

O panorama oferecido exerce a informação sob o método de caráter autoreflexivo, bem como uma crítica ferrenha ao processo econômico e jurídico do Brasil. O paralelo é feito indiretamente por a autora, com uma abrangência relacional das categorias permitindo um encontro interdisciplinar. A partir de suas contribuições, podemos inferir que, para deixarmos a ingenuidade - a qual nos conduz ao olhar sobre cargas subversivas em artefatos de mera reiteração ideológica - é preciso voltar os olhos para uma dimensão mais básica da sociedade brasileira: a transparência, a qual permite a produção libertária de cidadãos advindos principalmente pela maioria esmagadora, a classe trabalhadora.

Tal fator nos levará à constatação e contestação de certa homogeneidade de disposições sociais velados dos atores envolvidos, com consequências desastrosas que se revelam diariamente - a exemplo da desigualdade. Portanto, nada que não esteja presente nos demais campos sociais que exercem o trabalho da dominação, entre eles, o campo mercadológico, enfatizando o jurídico, cuja regularidade de classe salta aos olhos, e o político, que de representativo tende a ser apenas do poder econômico.

Por fim, a disposição das análises possibilita que as discussões eminentemente teóricas possam dialogar com os resultados das pesquisas empíricas até então divulgadas, o que mantém a abertura e ciência dos impactos da crise: queda do produto interno bruto, desemprego, imposições 
de reformas neoliberais, como as privatizações, e declínio da arrecadação tributária nos setores industriais e financeiros.

Recebido em: 30/11/2017

Aprovado em: 13/12/2017 